International Journal of Engineering \& Technology, $7(4.7)(2018) 78-81$
International Journal of Engineering \& Technology
SPC
Website: www.sciencepubco.com/index.php/IJET
Research paper

\title{
Implementation of Iso 9001, Iso 14001, Iso 45001 Requirements with the Systems of Electronic Document Turnover
}

\author{
Igor P. Balabanov, Fail F. Davletshin \\ Kazan Federal University \\ e-mail: balabanovip@mail.ru \\ e-mail: davletshin_fail@mail.ru \\ $+7(917) 8998877$
}

\begin{abstract}
In the modern actively developing conditions of globalization and informatization of production, and emergence of new technologies, only those firms have chances to remain at the market which find ways and means of optimization of processes in time. Adhering to the basic principles of the integrated system of management ensures the most natural and trouble-free functioning of all organizational structure. This paper covers the specifics of work with documentation, or the system of paper and electronic document flow, and with the application of an electronic document management system taking into account observance of requirements of documentary information management system. Adherence to ISM requirements for documentary information management is quite real with options of conducting document flow. Nevertheless, it is much simpler and more effective to perform with already introduced EDMS, and the effect of its use of subjects is higher when the enterprise scale and a number of staff involved in work with documentation are bigger. The maximum output can be achieved from electronic document flow introduction with an optimum ratio of the functions demanded in operation and if opportunities of the chosen system correspond to them.
\end{abstract}

Keywords Document management, ISM requirements, information dissemination, information retrieval.

\section{Introduction}

The purpose of this work is to carry out the comparative analysis of two types of document flow, being guided by requirements of the ISO 9001, ISO 14001, ISO 45001 standards (hereinafter integrated management system, or IMS) and to choose the most optimum options for passing a management system certification $[10,11]$ (further as CM). In order to distribute costs of labor functions in the most optimum way, the paper presents calculations on how quickly one employee will be able to cope with this or that process.

\section{Results and Discussion}

With growth of production and commercial relations, expansion of an enterprise and its product range need for streamlining the document flow and economy of the related expenses of work and time increases.

Rather effective method of optimization is introduction of the electronic document management system (EDMS) [7]. This approach to maintaining documentation is relevant for the organizations of different scale and influences a set of indicators, both quantitative and qualitative. It is possible to refer them to unproductive expenses of working hours, labor productivity of employees, costs of materials and resources [8,9], speed and transparency of information streams, and corporate culture in general.

Today there are also adherents of an electronic document management system and paper-electronic document management system (or file archive).
Many organizations are stopped before introducing EDMS by a question of its cost. However, it is worth noticing that today there is a great number of the Russian and foreign developers in IT market who offers services on introduction and service of EDMS within the different price range. On the average, the total cost of EDMS introduction is from several thousand to tens of thousands rubles per one workplace, and the annual cost of its subsequent ownership can reach $25-35 \%$ of initial investments. At the same time, free versions, which allow the organizations to begin to work with certain restrictions, are being released to benefit from an electronic form of document flow.

However, for a start it is necessary to address major factors of the EDMS choice:

1) Functionality of system, which needs to be created, and whether there is a need for scanning and recognition of documents.

2) The number of users, and of employees working at the same time.

3) Document flow volumes.

4) Geographical location of branches.

Answers to all these questions will help to became oriented when performing the choice of EDMS.

We will consider several main requirements to IMS for management of documents and records. Then we will compare on their basis approaches to observance of these requirements in two systems of document flow. 


\section{Distribution of information ensuring its availability, search,} and use

When introducing electronic and paper document flow, many organizations begin to face with a long time of documents coordination, complicated communications between departments, and violation of preparation terms for answers. The territorial remoteness of divisions can influence access to documents and terms of performance of tasks and will be connected with possible transport expenses, for example, if it is necessary to put signatures on original documents. For the paper archive to work effectively, it is necessary to organize in it an accounting of documents based on a card file, both in paper, and in electronic form for the scan copies. However, it does not protect from naught risks of loss of important documents, a long time of search of documents in archives Besides, the physical space for storage of documents in paper form occupies not a small item of expenditure in the budget of an organization.

The EDMS applications have an opportunity to keep the scanned documents automatically as soon as information comes to the organization in paper form. In further processes, paperless technologies are used, and all documentation becomes available with remote access on the Internet, including mobile devices. Besides, not only EDMS contains convenient tools for full work with a document, but it also protects users from repetitive production of hard copies, it is possible to create templates of documents that will considerably reduce the number of mistakes during the work with standard documents. Full text search by names and requisites of a document card, the adjusted search templates and convenient mechanisms of filtration of lists simplify and accelerate the system of search.

Distribution of data when using EDMS is carried out by means of modeling of processes in system. To develop a model of management and to make changes to processes are possible in the course of activity. There is an opportunity to plan the movement of documents and records on the set routes according to features of organizational structure of an enterprise. It reflects through which participants this document / record will pass along its route, which order and the nature of processing and also serial-parallel approach for their coordination is used. The electronic system allows the management to obtain data in that format, the place and time in which they are necessary. An interested person can always trace at what stage a document or record is what events took place earlier and by what documents these events were followed that provides control of performing discipline. Moreover, automatic calculation of KPI indicators (productivity of employees) is possible. For coordination, signing of the document or its version the digital signature is used. All this improves also quality of administrative decisions.

At the same time, there is also another side to the story. As well as any project, introduction of EDMS demands the special equipmen on which the system (software) will operate. For work with electronic document flow, it is necessary to have at least one server (depending on the level of the organization). If upon introduction of EDMS the mass translation of documents in an electronic look has been automated, the special scanner supporting the mode of stream scanning will be needed. Costs of optimization of business processes, change of standard documentation, and training of employees are inevitable [6].

\section{Ensuring sufficient information security}

The initial option of paper as a result of temporary influence or unforeseen emergencies can lose its integrity, at the same time a part of information will be lost what will cause an irreparable loss to business. Regarding safety and control over use of information with paper and electronic document flow files are also stored in encrypted form on the web server. An individual level of access can be assigned to each file in file archive; information from file archive is not recorded in a cache of the browser and each display of pages with files of archive leads to repeated loading of files from the server.

Data protection of EDMS is carried out by means of the login and the password to an account. Groups and roles of users should be created. There is a possibility of authority distribution, distributions of access rights at the level of the folder, control of relative access rights on organizational structure. It is possible to establish differentiations for documents: rights for viewing and changing for coordinating, claiming or other users. Backup copies of files are regularly created to ensure safety, as a result an opportunity is excluded that the document or record will be lost.

\section{Management of changes (versions)}

When using the electronic and paper scheme in the organization current versions of documents in file archive and all outdated versions store in paper archive together with the existing originals are kept. Therefore if an old version of the document is required, it is needed to address to a paper archive that in turn takes away a lot of time and distracts from the current productive work.

It can also be difficult to organize updating of documents as a human factor takes place: a performer can incorrectly place a new version of a document in file archive, or on the contrary, to lay out several versions of documents in the folder that will complicate search of a current version.

All similar searches of documents, waiting in receptions, repeated coordination, problems caused by low coordination with activity of related departments, repeated input and duplication of data represent a routine and not productive part of work. According to estimates of the consulting organizations, the share of such operations makes up to $30 \%$ of all working day.

Therefore, for productive work of system it is important to have accurately built process of introduction of new versions. Each employee working with documents and records is obliged to know how to carry out its requirements. The management needs to carry out regular internal audits of file archives and check the level of workers' knowledge.

EDMS can not to be confused with a large number of files with changes in them: documents can have an unlimited number of versions, but only one can be appointed relevant. Therefore, it isn't required to find the current time version. It is possible to attach an unlimited number of files of any format (including previous versions), to write comments to sections at the same time: all history of changes of the document is saved automatically. It is possible to see who, when and what changes / additions made.

\section{Working life. Maintenance and destruction order}

To maintain a working life when including into the archive an old version of a document, a date is fixed on it. Then, according to the schedule of documentation destruction (as a rule once in half a year, or once a year) an inspection of archive is carried out.

When using electronic system, there is no need to delete documents. It is enough to transfer them to the database where they will be available to viewing only. In case of need to remove documents through a certain term of time, there is an opportunity to establish removal in the automatic mode. Thus, a process of documentation destruction takes less time.

We will calculate how much working time it takes to perform standard operations connected with implementation of IMS requirements on the example of two organizations planning to undergo certification: LLC "Serp", which uses the system of paper and electronic document flow and LLC "Molot" which has applied the EDMS. The staff which constantly works with documents in both organizations is 200 people. We will choose a manday parameter which corresponds to day of work of one person as a unit of account of labor costs. 
Table 1:.

I. Distribution of information, ensuring its availability, search and usage

\begin{tabular}{|c|c|c|c|c|c|c|}
\hline Registration of documents & 3 & 1 & 5 & 3000 & 94 & 31 \\
\hline Transformation of the paper document to an electronic one & 8 & 1 & 5 & 3000 & 250 & 31 \\
\hline Search of documents with the known attributes & 7 & 1 & 200 & 200 & 583 & 83 \\
\hline Search of documents with unknown attributes & 120 & 5 & 50 & 20 & 250 & 10 \\
\hline Organization and preparation of meetings & 40 & 15 & 20 & 80 & 133 & 50 \\
\hline Reminders mailing on an approach to the document performance date & 15 & 0 & 2 & 400 & 25 & 0 \\
\hline Transfer of the document for execution/acquaintance & 20 & 3 & 20 & 70 & 58 & 9 \\
\hline Preparation of reports & 40 & 5 & 160 & 100 & 1333 & 167 \\
\hline Preparation of a document & 240 & 120 & 160 & 10 & 800 & 400 \\
\hline Coordination reports with heads of the organization & 240 & 30 & 150 & 12 & 900 & 113 \\
\hline
\end{tabular}

Coordination reports with heads of the organization

II. Ensuring sufficient information security

\begin{tabular}{|l|l|l|l|l|l|}
\hline Recovery of the lost document & 360 & 5 & 5 & 1 & 4 \\
\hline
\end{tabular}

III. Management of changes (versions)

Search of the previous version of the document

Search of the new version when duplicates appear

Correction of the report due to use of not the current version of the initial document

Coordination of changes by heads

IV. Working life maintenance and destruction order

Registration of the document in archive

Tracking a period of storage of the document

As it can be seen from table 1, the management of LLC "Serp" spends 5107 person-days a month for performance of the standard operations. LLC "Molot" on the same operations spends 958 person-days. It is possible to draw a conclusion that EDMS allows to save every month 4149 person-days counting on 200 people. If cumulative expenses of working hours in average are 4000 person-days (200 employees $* 20$ days in a month), in percentage terms, economy of working hours of employees will make:

$4149 / 4000 * 100=104 \%$.

In the presented example, it can be seen that the benefit from EDMS use is approximately twice higher, than from the system of file archive. And if to consider the fact that economic effect of EDMS introduction is directly proportional to a number of the users using it, then it becomes clear that, the more the organization and its state working directly in EDMS the more they economize. The calculations given above are conditional and approximate, however, they illustrate the basic principles of calculation. In practice more exact assessment is necessary considering, in particular, allocation of costs of working hours by types of documents, various level of the employee salaries, and the cost of introduction, licenses and use of the chosen EDMS.

In the modern actively developing conditions of globalization and informatization of production, and emergence of new technologies, only those firms have chances to remain at the market which in time find ways and means of optimization of processes. Adhering to the basic principles of the integrated management system ensures the most natural and trouble-free functioning of all organizational structure. This paper covers the specifics of work with documentation with the system of paper and electronic document flow and with the application of an electronic document management system taking into account observance of requirements of system of management regarding management of documentary information.

\section{Conclusion.}

To sum up, it is possible to draw a conclusion that to adhere to IMS requirements for documentary information management lis quite real with both options of conducting document flow. Never-

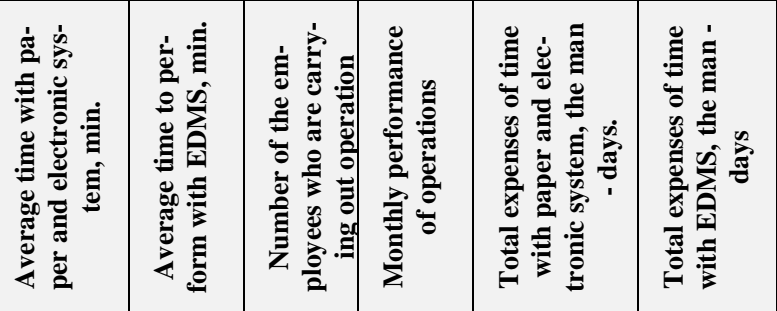

\begin{tabular}{|c|c|c|c|c|c|}
\hline 30 & 1 & 100 & 5 & 31 & 1 \\
\hline 40 & 0 & 20 & 2 & 3 & 0 \\
\hline 60 & 0 & 100 & 1 & 13 & 0 \\
\hline 180 & 20 & 150 & 10 & 563 & 63 \\
\hline 3 & 0 & 2 & 2000 & 25 & 0 \\
\hline 5 & 0 & 2 & 2000 & 42 & 0 \\
\hline & & & & $\mathbf{5 1 0 7 , 0 0}$ & $\mathbf{9 5 8 , 0 0}$ \\
\hline
\end{tabular}

theless, it is much simpler and more effective with already introduced EDMS, and the effect of its use for subjects is higher when the enterprise scale and a number of staff involved in work with documentation are bigger. The maximum output can be achieved from electronic document flow introduction with an optimum ratio of the functions demanded in work and opportunities of the chosen system answering to them. Therefore, before making a decision the management should also estimate the acquired benefit from reducing costs connected with innovations and also the investments enclosed in this project and term of their payback. Anyway, if an organization has chosen a way of constant improvement and seeks to reach the new status guaranteed to CM, then even a gradual transition to EDMS will bring positive results.

\section{Acknowledgement}

The work is performed according to the Russian Government Program of Competitive Growth of Kazan Federal University.

\section{References}

[1] Balasanyan. V.E. Electronic document flow - a basis of effective management of the modern enterprise//Secretarial business. 2002. No. 2.

[2] The paper "Electronic document flow. How to estimate economic efficiency of EDMS" URL: http://doc.ictonline.ru/articles/article1023/ (access date: 12.04.2017).

[3] Electronic library of management. URL "Corporate management": https://www.cfin.ru/ (access date: 13.04.2017).

[4] ECM - Journal. The Magazine about URL document flow. https://ecm-journal.ru/ (access date: 14.04.2017).

[5] A.I. Bochkarev, I.P. Balabanov. Training the employees of primary level technological production in handling of analysis and statistical process management tools / / Problems of modern pedagogical education. Ser.: Pedagogy and psychology. - Collection of scientific works: -Yalta: RIO GPA, 2017. - Ed. 55.- P. 5.- pp. 3-9.

[6] Vu Van TUAN Communicative Competence of the Fourth Year College Students: Basis for proposed English Language Program, Astra Salvensis, Supplement No. 2, 2017, p. 45 
[7] Irina MALGANOVA, Andrey ERMAKOV, Development of heating Devices from Polypropylene, Astra Salvensis, Supplement No. 2, 2017, p. 93

[8] Kasyanov S.V., Kondrashov A.G., Safarov D.T. Research of characteristics of wearproof coating for cutting tools / INTERFINISHSERIA 2014: International Conference on Surface Engineering for Research and Industrial Applications. 2014. P. 124

[9] Mogilevets V.D., Savin I.A. Development of the enterprise's IMS for compliance with QMS and lean manufacturing standards / V.D. Mogilevets, I.A. Savin // Competence. -2017. - No. 5 (146). - Pp. 28-31.

[10] Mogilevets V.D., Savin I.A. Development of the enterprise's IMS for compliance with QMS and lean manufacturing standards / V.D. Mogilevets, I.A. Savin // Competence. -2017. -No 6 (147). - pp. 3843

[11] 1 Shatilova L.M., Borisova V.V., Kasatkina O.A. (2018). Representation of the linguistic and cultural concept "lie" in the French and Russian language picture of the world, 34(85), Pp. 194-212.

[12] 2 Bakhyt S., Kalimbetov B., Khabibullayev Z. (2018). Possibilities of Mathematical Problems in Logical Thinking, Development of Secondary Education Pupils, 34(85), P.p. 321-338.

[13] Safarov, D.T., Fedorov, K.A., Ilyasova, A.I, 2016. Algorithms development of making special techniques in APQP manufacturing process of automotive components IOP Conference Series: Materials Science and Engineering 2016. 